\title{
Mitbringsel aus Sansibar
}

\section{Hier steht eine Anzeige.}

_ Eine 52-jährige Patientin stellt sich mit inflammatorischen Hautveränderungen und starkem Pruritus am Stamm und in den Axillae vor. Beides war kurz nach ihrer Rückkehr aus dem sechswöchigen Badeurlaub auf Sansibar aufgetreten.

Die körperliche Untersuchung zeigt disseminiert Papeln und Nodi zwischen $3 \mathrm{~mm}$ und 1,5 cm im Durchmesser mit umgebendem Erythem und teils zentralem Porus oder Kruste (Abb. 1). Die regionalen Lymphknoten weisen eine leichte Schwellung auf. Die Nodi selbst sind derb palpabel und mäßig druckdolent. Die Patientin hat keine weiteren Symptome, die z. B. auf eine Infektionskrankheit hinweisen. Auch Muskelschmerzen liegen nicht vor. Ebenso hat sie keine relevanten Vorerkrankungen und nimmt keine Medikamente regelmäßig ein.

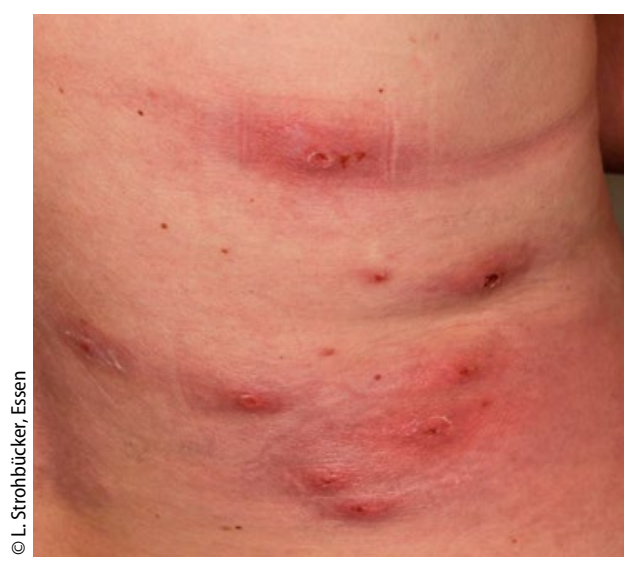

Abb. 1 Entzündliche Papeln und Nodi am Rumpf rechtsseitig.

\section{Worum handelt es sich?}

Es handelt sich um eine furunkuloide Myiasis, konkret um die primär kutane Form. Sie tritt in Afrika und Südamerika auf.

Durch vermehrtes Reisen in subtropische Gebiete steigt die Inzidenz des Krankheitsbilds auch bei Europäern. Verursacht wird die furunkuloide Myiasis durch die Larven der Tumbufliege (Cordylobia anthropophaga), die die Subkutis penetrieren und sich dort entwickeln.

Klinisch zeigt sich die temporäre kutane Manifestation in mindestens einem sich langsam vergrößernden, schmerzhaften, häufig furunkuloiden Nodus. Die Nodi weisen zentral oft eine kraterförmige Ulzeration auf - die Atemöffnung für die Larve. Ergänzend zeigen sich klinisch gehäuft Schwellungen der regionalen Lymphknoten. In der Literatur werden vermehrt Muskelschmerzen bei den Betroffenen beschrieben. Gelegentlich berichten Patienten von spürbaren Bewegungen in der Haut und Juckreiz. Selten treten Fieber oder Unwohlsein auf. Prädilektionsstellen sind Nacken, Rumpf und Axillen.

- Hautarzt 2016;67(8):667-669 